\title{
Massive pulmonary arteriovenous malformation presenting with tamponading haemothorax
}

A 71-year-old woman presented with a l-week history of dyspnoea, right pleuritic chest pain and bilateral ankle oedema. There was no history of cough, fever or haemoptysis. Her body mass index was $>30$. Her jugular venous pressure was raised with reduced air entry over the right lung base. She was anaemic (haemoglobin $6.8 \mathrm{~g} / \mathrm{dl}$, mean corpuscular volume 67) with type II respiratory failure $(\mathrm{pH} 7.40$, oxygen tension $9.30 \mathrm{kPa}$, carbon dioxide tension $9.32 \mathrm{kPa}$ on 0.5 fraction of inspired oxygen). Chest radiography revealed a moderate right pleural effusion. A chest drain was inserted in the emergency room and 2 litres of bloody effusion was drained. A subsequent contrast-enhanced CT scan of the chest revealed a probable pulmonary arteriovenous malformation (PAVM) in the right lower lobe and a compressing organised haemothorax with significant mediastinal shift (fig lA). Pulmonary angiography confirmed a massive PAVM with multiple large feeding arteries and other smaller PAVMs in the right lower lobe (fig $1 \mathrm{~B}$ ). Primary embolisation failed to secure haemostasis and subsequent urgent exploratory thoracotomy showed a PAVM involving predominantly the lower and middle lobes and gross active bleeding once the clot was evacuated. This was controlled by simple oversewing of the bleeding area. The patient then underwent serial PAVM embolisations to which she responded well (fig 2).

Spontaneous haemothorax is a rare complication of PAVM. ${ }^{1}$ To our knowledge, such massive haemothorax causing tamponading with mediastinal shift has not previously been reported. Surgical resection of PAVM is indicated in patients who have intrapleural rupture of PAVM. ${ }^{2}$ In our case, combined surgical management of the acute bleed followed by catheter embolisation of the PAVM led to a successful outcome.

A A Khan, I Hunt, K Hamdane, J Tambiah, R P Deshpande Department of Thoracic Surgery, Guy's Hospital, Kings College London, UK

J F Reidy

Department of Interventional Radiology, Guy's Hospital, Kings College London, UK Competing interests: None declared.

doi: $10.1136 /$ thx. 2006.071852
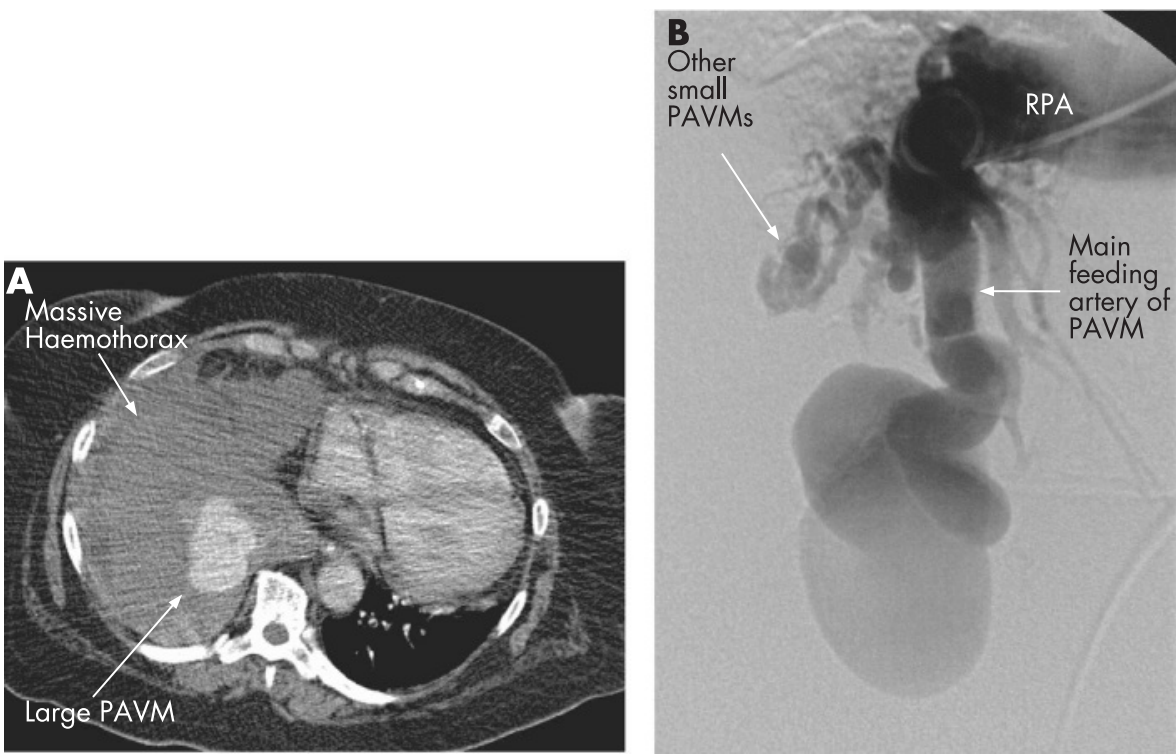

Figure 1 (A) CT scan showing pulmonary arteriovenous malformation (PAVM) and extensive tamponading pleural collection in the right hemithorax. (B) Pulmonary angiogram: selective injection into the right pulmonary artery (RPA) showing the middle and lower zones. There is a very large tortuous artery feeding a massive PAVM. Note also other smaller arteriovenous malformations.
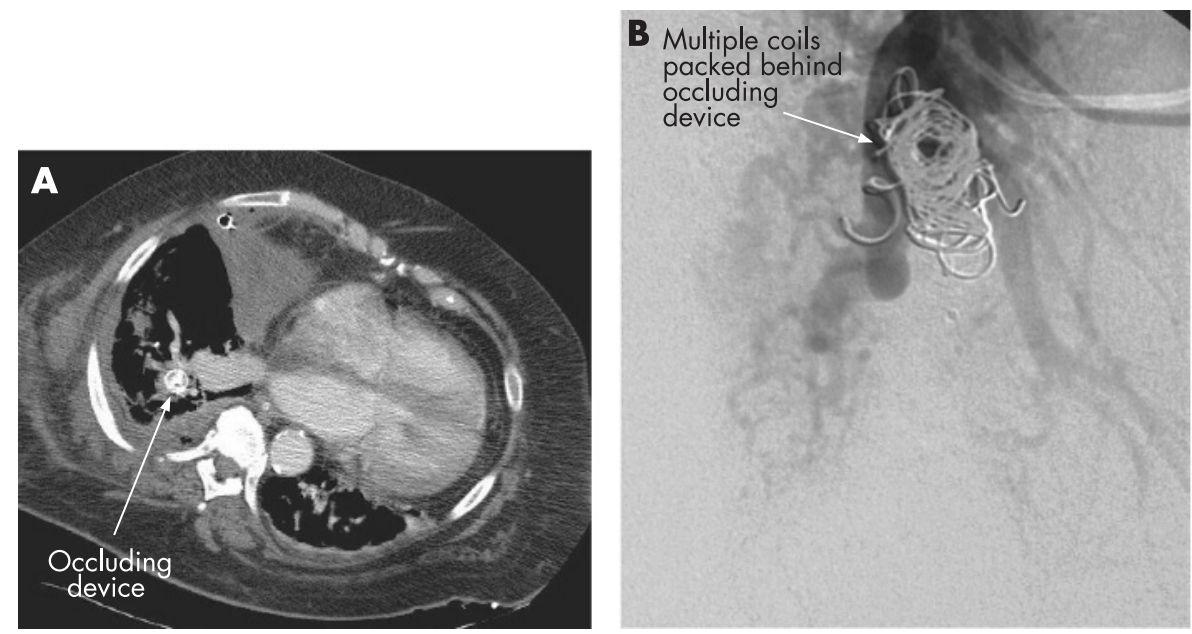

Figure 2 (A) CT scan showing the Amplatzer occluding device (AGA Medical Corporation, Plymouth, Minnesota, USA). (B) Pulmonary angiogram following placement of the Amplatzer occluding device in large feeding artery. Multiple coils have been packed behind it. This has effectively occluded the large feeding artery.

Correspondence to: Mr I Hunt, Department of Thoracic Surgery, Guy's Hospital, Kings College London, St Thomas' Road, London SEI 9RT, UK; ianjhunt@gmail.com

\section{References}

1 Edinburgh KJ, Chung MH, Webb WR. CT of spontaneous hemothorax from intrapleural rupture of a pulmonary arteriovenous malformation. AJR Am J Roentgenol 1998;170:1399-400.

2 Khurshid I, Downie GH. Pulmonary arteriovenous malformation. Postgrad Med J 2002;78:191-7.

\section{Learning points}

- Pulmonary arteriovenous malformation may present acutely with massive spontaneous haemothorax. and percutaneous embolotherapy may lead to successful outcomes in high risk candidates.
- Combined surgical intervention 